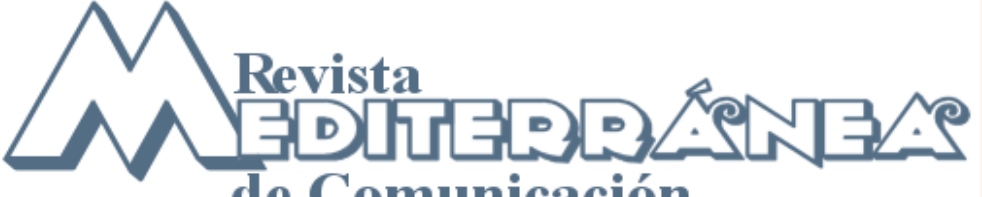

\section{Hacer televisión desde la comunicación, propuesta de rediseño de la identidad visual corporativa de Telecubanacán}

\section{To make television from the communication, proposal of I redraw of the corporate visual identity of Telecubanacán}

\author{
Lic. Oneibys Torres Figueroa \\ Licenciada en Comunicación Social en la \\ Universidad Central "Marta Abreu" de las Villas \\ Cuba \\ oneibys@telecubanacan.icrt.cu \\ Dr. Kirk Díaz-Guzmán Corrales \\ Profesor Adjunto de Fundamentos de Publicidad. \\ Universidad Central "Marta Abreu" de las Villas Cuba
}

\section{Resumen}

La presente investigación se desarrolló en el telecentro provincial "Telecubanacán", del Sistema de la Televisión Cubana, con el objetivo de proponer el diseño de su identidad visual a partir de identificar los elementos que contribuyan a formar la imagen deseada. El estudio se abordó desde la metodología cualitativa y el método investigación-acción, desde abril de 2009 a mayo de 2010.

Las técnicas de investigación empleadas fueron: análisis de documentos, observaciones participantes, entrevistas semiestructuradas, sesiones grupales y briefing operativo. Consejo de Dirección, fundadores, promociones recientes de la Universidad Central "Marta Abreu" de la Villas en el telecentro y expertos fueron las unidades de análisis.

Se expusieron puntos de vista en torno a la identidad visual corporativa y su integración a las acciones de comunicación como verdadero valor añadido, distinguiendo elementos básicos del diseño para el caso particular de la televisión.

Inicialmente, fue caracterizada la identidad visual de Telecubanacán. Para la propuesta de diseño se precisaron los elementos de identidad visual necesarios, a partir de la imagen deseada de ser un telecentro de proximidad, cercano a las prácticas comunitarias y elevar su status e indicadores de prestigio, reconociéndose como un colectivo profesional.

Se propuso la aplicación de la nueva identidad visual en los distintos espacios de emisión y la disposición de sus aplicaciones en la arquitectura de la organización. Ello devino un elemento integrador que los hace singulares, comunes, sinérgicos y coherentes en aras de una emisión integrada de comunicación. 


\section{Abstract}

The present investigation was developed in the provincial channel "Telecubanacán", Sistem of Cuban Television, with the objective of proposing the design of its visual identity starting from identifying the elements that contribute to form the desired image. The study was approached from the qualitative methodology and the method investigation-action. It was carried out from April 2009 to May 2010.

The research techniques used were: analysis of bibliography, participant's observation, semistructured interviews, groupal sessions and operative briefing. The leading staff, founders, recent promotions of the Central University "Marta Abreu" de Las Villas in the channel and experts were the analysis units.

Points of view about the corporative visual identity and their integration to the communication actions were exposed as a true added value, distinguishing basic elements of the design for the specific case of television.

At first, the visual identity of Telecubanacán was characterized. For the design proposal the necessary elements of visual identity were determined, starting from the desired image of being a TV channel close to the community practices to elevate its status and indicators of prestige, recognizing it as a professional staff.

The application of the new visual identity was proposed in the different broadcasting spaces and the disposition of its applications in the architecture of the organization was also proposed. The new visual identity became in integrative element that makes the channel singular, common, and coherent for the sake of an integrated broadcast of communication.

\section{Palabras claves}

Comunicación; identidad visual; imagen corporativa; televisión; Cuba.

\section{Key Words}

Corporative communication; corporative visual identity; corporative image; television; Cuba.

Sumario: 1. Introducción. 2. Descripción del escenario de investigación. 3. Paradigma metodológico que sustenta la investigación. 4. Definición de métodos de investigación. 5. Definición de categorías e indicadores. 6. Decisiones muestrales. 6.1 ¿A quiénes aplicar los instrumentos de investigación? La selección de informantes. 7. ¿Qué técnicas e instrumentos permiten estudiar la Identidad? 8. ¿Cómo procesar las informaciones obtenidas? 9. ¿Posee validez y fiabilidad la investigación cualitativa? 10. Resultados. 11. Conclusiones. 12. Recomendaciones. 13. Referencias Bibliográficas. 14. Referencias en la red. 15. Sitios visitados.

Summary: 1. Introduction. 2. Description of research 3. Research Questions. 4. Method. 5. Shared fields between the advertising and the news language information. 6. Techniques of the advertising language applied to the news. 7. The use of audiovisual language in informational messages. 7.1 Shots, transitions. 7.2 Integration of the text. 7.3 Ellipsis. 7.4 Music. 8. Conclusions. 9. Bibliography. 10. Internet links. 


\section{Introducción}

Para unos, seductora, misteriosa; otros la creen, virtual o auténtica. Para algunos simplemente es un juego; para funcionarios, peligrosa y hasta temible; para artistas, éxito o frustración. Lo cierto es que hoy la tecnología pone la palabra, la imagen y el sonido al alcance de todos. Entre dificultades, la televisión encontró su propio lenguaje y hoy es, el medioambiente audiovisual con el que se interactúa todo el tiempo y de forma automática. Esta presencia penetrante, poderosa de mensajes en imágenes y sonidos produce un impacto de peso en el comportamiento social y desarrollo intelectual. Bien puede observarse esta incidencia en las acciones cotidianas, sin que ello signifique negar el rol activo que podrían asumir los receptores o consumidores de televisión.

Es una paradójica sensación de cercanía lejana. Cada vez más lo que pasa en la televisión "mapea" nuestra experiencia, - lo que no existe en la televisión, ¿existe en la realidad? - Ilegan a cuestionarse muchos. Los programas de la tele, como se acostumbra llamar, son fuente primordial de información, formación o desinformación, muchos de los temas de conversación cotidianos giran en torno de los relatos televisivos. La televisión es también una expresión artística, que como ninguna otra, es objeto de juicio de muchas personas, y las opiniones pueden deberse a la inmediata y sencilla impresión al sentarse frente a la pantalla y decir: - me gustó o no me gustó tal o más cual programa-.

La televisión al igual que la radio y la prensa, entre los medios de comunicación de masas, es considerada portadora del discurso identitario desde el poder en cualquier nivel de organización social. Sin embargo, el fenómeno de percepción del medio, si bien en la radio es parcial, en la televisión es más completo, es masivo. Por eso, para hacer televisión debe pesar la proyección creativa, inteligente y efectiva de una identidad visual coherentemente definida por el medio como función necesaria en su desarrollo, a través una emisión eficaz de comunicación desde y para la sociedad. Implica dar un viraje en su concepción como un medio en sí, como soporte tecnológico, y acercarlo a las prácticas sociales, a las prácticas comunicativas.

Hoy día los telecentros municipales y provinciales en Cuba deben ser la expresión auténtica de lo regional y comunitario. El telecentro provincial "Telecubanacán" tiene la misión de informar, educar y entretener, desde una perspectiva esencialmente cultural para satisfacer los intereses de los diferentes públicos de la provincia de Villa Clara. Su proyección es guiada por la visión de ser un telecentro de proximidad cercano a las prácticas comunitarias y elevar su status y los indicadores de prestigio, reconociéndose como un colectivo profesional.

Ante la carencia de una identidad visual definida que "Telecubanacán" proyectara hacia sus públicos, era necesario proponer un programa de identidad visual. Tomando en consideración las necesidades de esta organización y las potencialidades de la Comunicación Social para abordar dicha problemática, se generó el problema científico de la investigación: ¿Cómo proponer el diseño de la identidad visual de Telecubanacán a partir de identificar los elementos que contribuyan a formar la imagen deseada? 
El objetivo general formulado fue el siguiente: Proponer el diseño de la identidad visual de Telecubanacán a partir de identificar los elementos que contribuyan a formar la imagen deseada.

Los objetivos específicos que guiaron el trabajo fueron:

- Caracterizar la identidad visual actual de Telecubanacán.

- Precisar los elementos de identidad visual necesarios para la propuesta de diseño a partir de la imagen deseada por Telecubanacán.

- Proponer la aplicación del nuevo diseño de la identidad visual en los distintos espacios de emisión de Telecubanacán.

- Proponer la disposición de las aplicaciones visuales en la arquitectura de la organización.

"Cada día hay que tener una buena idea, una excelente idea, para alimentar la voracidad del más triturador de los medios de comunicación social" (González, 1997, p. 13). Los resultados de la presente investigación contribuirán al desarrollo y modernización de los mensajes visuales de Telecubanacán. Para ello es determinante la incorporación de técnicas de expresión gráfica, guiadas por el uso pertinente de las nuevas tecnologías y tendencias a considerar respecto a los elementos audiovisuales. La estructuración de la identidad visual corporativa del telecentro villaclareño es el elemento integrador que los hará comunes, sinérgicos y coherentes en el logro de la eficacia de sus mensajes. Esto debe incentivar la inteligencia, la habilidad y el talento en beneficio de la planificación de estrategias que a largo o corto plazo, conciban como función necesaria en su desarrollo una emisión integrada de comunicación.

Durante la revisión bibliográfica y documental se consultan fuentes teóricas sobre comunicación, identidad e imagen en las organizaciones y tesis de Diploma, Maestría y Doctorado de la Facultad de Comunicación de La Habana, de Santiago de Cuba y de la Universidad Central "Marta Abreu" de Las Villas. Además se emplean las fuentes de información directas (criterio de expertos e informantes clave) y las indirectas: documentos oficiales y normativos de la organización objeto de estudio, Telecubanacán.

La organización del marco teórico obedece a consolidar aspectos coincidentes que definen la imagen, la comunicación y la identidad corporativa, específicamente, se exponen puntos de vista en torno a la identidad visual, distinguiendo los elementos básicos del diseño a tener en cuenta para el caso particular de la televisión.

Así como las personas tienen características que las hacen resaltar con respecto de otras, lo mismo sucede con las organizaciones. De la misma manera como cada mañana conscientes de la imagen que queremos proyectar-, no dejamos al azar el peinado del cabello, la limpieza y la ropa a usar ese día, la imagen organizacional no debe ser dejada al azar y debe emanar directamente de nuestra identidad para ser creíble.

Anteriormente las organizaciones simplemente se preocupaban por hacer bien lo que tenían que hacer; enfocaban todos sus esfuerzos hacia la productividad o hacia el control de la calidad. Desde luego ello sigue siendo esencial para el buen funcionamiento pero, 
¿de qué sirve hacer las cosas bien si nadie se entera de ello? Los medios de comunicación masiva adquieren importancia inusitada en la comunicación organizacional. Esencialmente, la televisión encabeza el denominado "cuarto poder" en la sociedad moderna y a la misma la vez, los telecentros tienen que posicionarse estratégicamente en un mundo de información y de imágenes, preocupándose también por la percepción que tienen sus públicos. Muchos canales pueden inundar con imágenes las mentes de los televidentes, pero en el momento en que el espectador se siente frente a la pantalla sólo reconocerá la firma de aquel que "imagina" como suyo porque lo identifica como tal.

Los elementos identitarios determinados por la cultura organizacional, conforman una personalidad única, intransferible, pero no estática de un telecentro provincial. Los elementos visuales proyectan a sus públicos la suma de lo qué es y lo qué hace; la televisión a la vez que dice (qué es y qué hace), dice qué son y qué hacen los demás, conformando la opinión pública. Se establece una relación más estrecha entre la imagen interna y la imagen pública, se acorta el camino por el propio fenómeno masivo de la percepción. El rediseño de los signos visuales de un telecentro entra en su nivel arquitectónico, el más exterior y visible de su cultura, no implica cambios en sus presunciones básicas ni en los valores y no se habla pues, de un nuevo telecentro.

\section{Descripción del escenario de investigación}

El telecentro provincial "Telecubanacán" se funda en Santa Clara, Cuba el 5 de noviembre de 1984. Es el tercer telecentro del país en crearse, después de Santiago de Cuba (1968) y Holguín (1976). Actualmente todas las provincias del país disponen de uno de su tipo.

En sus inicios se convierte en Centro Regional de Información del canal nacional "Tele Rebelde" para el territorio central de Cuba, que incluyó a las provincias de Cienfuegos, Sancti Spíritus y Villa Clara. Durante 14 años Telecubanacán se convierte en voz e imagen del desarrollo económico, político, social y cultural del centro del país. El 13 de agosto de 1998 nace Centrovisión Yayabo para el territorio espirituano y el 5 de septiembre de 2000, Perlavisión para los cienfuegueros. Entonces, Telecubanacán pasa a ser un telecentro de carácter provincial, con transmisiones diarias de lunes a viernes de 12.00 a 12.30 y de 5:00 a 6:00 de la tarde.

Con el objetivo de reflejar el acontecer del territorio villaclareño, su cultura y tradiciones, durante las 7 horas y media de transmisión semanal ofrece a sus telespectadores 14 espacios que abarcan los distintos perfiles (histórico, juvenil, cultural, infantil, informativo, deportivo, campesino, de orientación social, una revista de variedades y un noticiero de 12 minutos diarios). Además transmite los fines de semana por la frecuencia del canal 57. Laboran en su equipo habitual periodistas, camarógrafos, ingenieros, locutores, directores de programas, editores, comentaristas deportivos, realizadores de imágenes y productores.

Telecubanacán realiza su gestión con la misión de satisfacer las necesidades informativas, educativas y de entretenimiento de la población de la provincia de Villa Clara, con una programación diaria de televisión, partiendo de la cultura y tradiciones del 
territorio y las distintas comunidades que lo integran. Las necesidades de producción se vinculan a las características del territorio, aspecto diferenciador como telecentro provincial de las televisiones nacionales. Además se reporta para el resto del país, a través del Sistema Informativo de la Televisión Cubana, la realidad del territorio villaclareño.

La programación en Telecubanacán se concibe de acuerdo a una Política de Programación de la Radio y la Televisión Cubana (1998), actualizada en el año 2007, puesto que al Instituto Cubano de Radio y Televisión (ICRT) corresponde como parte de las responsabilidades que le confiere el Estado Cubano en su carácter de rector de todas las actividades de ambos medios de difusión, la elaboración, ejecución y control de la Política de Programación más factible para lograr los objetivos que determinan su función ideológica y educativo-cultural al servicio del pueblo y del interés de la sociedad, todo lo cual está así refrendado en la Constitución de la República de Cuba.

\section{Paradigma metodológico que sustenta la investigación}

Ninguna perspectiva metodológica es más útil que otra, todo depende del contexto de investigación. Varias propuestas de estudios en comunicación se orientan desde la perspectiva cuantitativa, pero el alcance de la presente investigación trasciende la demostración mediante datos numéricos, la generalización y la deducción. La perspectiva cualitativa ofrece mayores posibilidades por ser más flexible y menos reduccionista, en tanto, proceso complejo que supera el modelo transmisivo de información.

Lo que distingue el paradigma positivista del humanista no son las técnicas empleadas ni el poco uso de datos numéricos, ni la intención de inducir en vez de generalizar, sino la manera en que se construye el conocimiento, la flexibilidad apreciada al concebirse según avanza la investigación; pues esta última se orienta al proceso, no a los resultados. Baste recordar que un paradigma no se define sólo por la metodología, sino por su ontología y por los presupuestos epistemológicos que asuma.

La indagación y construcción del conocimiento con un enfoque cualitativo, se estructura a partir de los hallazgos sucesivos que se van realizando durante el transcurso de la investigación. La validación de las conclusiones se hace a través del diálogo, la interacción y la vivencia, que se van concretando mediante consensos nacidos de los procesos de observación, reflexión, sentido compartido y sistematización.

\section{Definición de métodos de investigación}

De la elección del método de investigación depende el transcurso del estudio. "Ningún método es igualmente adecuado para todos los propósitos. La elección del método de investigación debe estar determinada por los intereses de la investigación, las circunstancias del escenario o de las personas a estudiar, y por las limitaciones prácticas que enfrenta el investigador". (Taylor y Bogdan, 1998, pp. 104). 
Es usual que se confundan los términos método y técnica en cuanto a su alcance. "Un método es un procedimiento general orientado hacia un fin, mientras que las técnicas son diferentes maneras de aplicar el método y, por lo tanto, es un procedimiento más específico que un método." (Cazau, 2006, pp.11)

Dentro de las Ciencias Sociales se ha hecho uso de una multiplicidad de métodos, incluso dentro de un mismo estudio. Entre estos se destacan: la fenomenología, la etnografía, la teoría fundamentada, la etnometodología, la investigación-acción y el método biográfico. Se considera que el método más a fin con los propósitos de investigación es la investigación-acción, concebida como una actividad integral que combina la investigación social, el trabajo educativo y la acción, su objetivo último es la transformación e implica la participación activa de los miembros de la organización.(Alonso y Saladrigas, 2002, p. 59)

\section{Definición de categorías e indicadores}

Categoría analítica: Elementos de identidad visual.

Definición conceptual: Es el conjunto coordinado de signos visuales mediante los que la organización comunica sus elementos identitarios. Por medio de los cuales la opinión pública reconoce instantáneamente y memoriza a una entidad 0 un grupo como institución. (Costa, 2001)

Los elementos de identidad visual son: Nombre, identificador o imagotipo, logotipo, gama cromática, tipografía, slogan.

Definición operacional: Identidad visual de Telecubanacán es el conjunto armonizado de signos visuales que lo distingue.

\section{Indicadores:}

- Identificar los elementos de identidad visual que contribuyan a formar la imagen deseada por Telecubanacán.

- $\quad$ Proponer el diseño de la identidad visual.

- Proponer la aplicación del nuevo diseño de la identidad visual en los distintos espacios de emisión de Telecubanacán.

\section{Decisiones muestrales.}

La muestra de informantes clave: se consideran los criterios de amplia participación en la cultura de la organización, decisor en la coordinación de acciones administrativas, persona a la cual se considera testigo por su permanencia en la organización y vivencias, que logra aportar información que necesitamos, da fe y corrobora, por lo que adquiere un nivel de fiabilidad; además la participación activa de un staff joven considerado por la organización una fortaleza. Se trabaja con el Consejo de Dirección de Telecubanacán, con fundadores y promociones recientes de la Universidad Central "Marta Abreu" de las Villas que forman un staff joven con reconocidos resultados en el desempeño. Con una 
representación de todos los departamentos del telecentro se forma un equipo asesor con el que se organizan todas las sesiones grupales, se aplica el briefing operativo y se conforma un grupo de gestión encargado de las propuestas creativas.

La muestra de expertos: se considera necesario la opinión de individuos expertos en el tema teniendo en cuenta la experiencia, formación profesional, especialización en el tema, vínculo con el medio televisivo, resultados notables en la trayectoria, disposición para colaborar con la investigación y tiempo disponible para ofrecer informaciones; son seleccionados cinco expertos: dos diseñadores gráficos especializados en audiovisual, un realizador de televisión, un especialista en comunicación y un profesor de imagen. Además de los expertos, son consultados tres diseñadores del territorio, miembros de la Asociación Cubana de Comunicadores Sociales, para evaluar las propuestas creativas, valoración a tener en cuenta por el grupo de gestión al defender una u otra alternativa frente a los intereses de la dirección de Telecubanacán.

Para caracterizar la identidad visual actual se tienen en cuenta los siguientes elementos:

- $\quad$ Aplicación de diagnósticos y auditorías precedentes.

- Existencia del Manual de Identidad Visual.

Estructura.

Signos visuales.

Nombre.

Logotipo.

Imagotipo o Identificador.

Gama cromática.

Slogan.

Tipografía.

Aplicaciones en la gráfica.

Normas de aplicación.

Aplicación. 


\section{1. ¿A quiénes aplicar los instrumentos de investigación? La selección de informantes}

Igualmente, de la pertinencia de esta etapa dependen los resultados finales. En cuanto a la determinación del universo de estudio, en los métodos cualitativos no se puede hablar de definición de una muestra porque no existe una representación estadística de dicho universo, ya que la información se extrae a partir de un número pequeño de personas, aunque sí de una representación tipológica, la cual, dicho sea de paso, es mucho más útil en la investigación sobre la imagen corporativa en la que es necesario evaluar la diversidad de opiniones de los públicos con un cierto nivel de implicación en la organización. (Villafañe, 1999, pp. 43). Por eso suelen utilizarse más en estudios cualitativos las muestras no probabilísticas.

"Frente al muestreo probabilístico, la investigación cualitativa propone estrategias de selección de informantes que suponen una selección deliberada e intencional. Las personas o grupos no se seleccionan al azar para completar una muestra de tamaño $n$, se eligen uno a uno de acuerdo con el grado en que se ajustan a los criterios o atributos establecidos por el investigador." (Rodríguez, 2004, p. 135)

La selección de informantes tiene un carácter dinámico, progresivo, secuencial, porque se extiende durante el desarrollo de la investigación a través del uso de diversas estrategias según las nuevas informaciones que emergen, las nuevas preguntas que se formule el investigador y las necesidades de contrastar datos para garantizar la confiabilidad y veracidad de los resultados.

Los informantes claves de la investigación seleccionados son:

- $\quad$ Consejo de Dirección de Telecubanacán.

- $\quad$ Fundadores del telecentro.

- $\quad$ Promociones recientes de la Universidad Central "Marta Abreu" de la Villas en el telecentro.

\section{7. ¿Qué técnicas e instrumentos permiten estudiar la Identidad?}

"Las técnicas cualitativas de investigación tienen en cuenta el marco de referencia del análisis, aportan un conocimiento rico y profundo de los hechos y explican las causas que los provocan. Establecen, en este sentido, una realidad dinámica del fenómeno estudiado, son flexibles e inductivas." (Villafañe, 1999, pp. 43)

Revisión bibliográfica y documental: Es una forma de indagación que contempla la revisión, selección, análisis, evaluación y reorganización de la información relativa al objeto de estudio. Permite la sistematización y el acceso directo al conocimiento teórico acumulado sobre el tema de investigación. Se desarrolla como técnica de investigación con los siguientes objetivos: reflexionar sobre imagen, comunicación, e identidad, tres categorías fundamentales dentro de la estrategia de la organización, revisar 


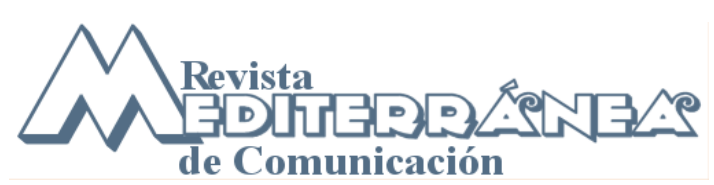

ISSN 1989-872X - Año2 (2011), pp. 140-170

investigaciones anteriores sobre el tema, caracterizar la identidad visual actual de Telecubanacán.

Se aplica a:

- Bibliografía sobre Comunicación, Identidad e Imagen Corporativas.

- Tesis de diplomas, maestrías y doctorados de la Universidad Central "Marta Abreu" de Las Villas y la Facultad de Comunicación Social de la Universidad de La Habana y la Universidad de Oriente.

- Documentos provenientes del Instituto Cubano de la Radio y la Televisión.

- Documentos de la organización.

La observación participante: Es una de las técnicas específicas declarada por (Alonso y Saladrigas, 2002, p. 53) para el método de investigación-acción. Una técnica de recogida de información muy útil en el estudio de la cultura y del comportamiento corporativo, basada en la convivencia en el centro de trabajo del investigador con los sujetos analizados. Su presencia tiene que ser discreta, procurando no inmiscuirse más de lo necesario en el desenvolvimiento de los sujetos que se analizan. (Villafañe, 1999, p. 44)

Es una de las técnicas empleadas en las investigaciones sociales por la posibilidad que brinda al investigador de conocer escenarios en profundidad y contrastar las informaciones obtenidas por medio de otras técnicas de investigación. Se reconoce que en las observaciones, el instrumento de medición es el propio investigador, por lo que debe tratar de observar e interpretar las situaciones con la mayor objetividad posible

Este proceso de observación tiene una estructura flexible y adaptable a las diferentes facetas que presente el fenómeno en estudio. En la observación participante el observador o investigador asume el papel de miembro del grupo, comunidad o institución que está investigando, y como tal, participa en su funcionamiento cotidiano. En este estudio la aplicación del instrumento responde a los objetivos: caracterizar la identidad visual actual de Telecubanacán y analizar la proyección de la identidad visual a través de la programación.

Como parte del estudio preliminar para caracterizar los elementos gráficos y visuales que apoyan el concepto de identidad asumido por la organización, el análisis se realiza a través de la siguiente categoría:

- Existencia del Manual de Identidad Visual. Estructura.

Subcategorías (signos visuales):

Nombre.

Logotipo.

Imagotipo o Identificador.

Gama cromática.

Slogan. 
Tipografía.

Aplicaciones en la gráfica.

Se considera necesario el monitoreo de la transmisión televisiva del telecentro para analizar la proyección de su identidad visual, teniendo en cuenta las posibilidades que puede ofrecer respecto a: uniformidad, coherencia e integración de los mensajes diversos por la temáticas.

La entrevista semiestructurada: Es una técnica muy usada en las investigaciones sociales por la cantidad de información que revela y por la oportunidad que tiene el investigador de explorar los sentidos de las personas entrevistadas así como la oportunidad de retroalimentación, de reformular preguntas y aclarar lo incomprendido de primer momento.

Entrevista semiestructurada a fundadores del telecentro: Persigue los objetivos de caracterizar los años fundacionales de Telecubanacán, explorar la identidad visual del telecentro desde su fundación, conocer el origen del nombre, identificar los signos visuales utilizados y su justificación, así como los responsables a cargo de los diseños y propuestas creativas, caracterizar la identidad visual actual de Telecubanacán e identificar los elementos de identidad visual que contribuyan a formar la imagen deseada por Telecubanacán.

Entrevista semiestructurada al Consejo de Dirección: Con los objetivos de explorar la concepción de imagen que tienen los directivos del telecentro, determinar la importancia que los directivos atribuyen a la identidad que un telecentro proyecta, caracterizar la identidad visual actual de Telecubanacán e identificar los elementos de identidad visual que contribuyan a formar la imagen deseada por Telecubanacán.

Entrevista semiestructurada a las recientes promociones de la UCLV en el telecentro: Con los objetivos de caracterizar la identidad visual actual de Telecubanacán e identificar los elementos de identidad visual que contribuyan a formar la imagen deseada por Telecubanacán.

Dinámicas grupales: Es una de las técnicas específicas declarada por (Alonso y Saladrigas, 2002, p. 53) para el método de investigación-acción Esta técnica, originalmente formalizada por Kurt Lewin, se basa en los postulados de la teoría de la Gestalt, uno de cuyos conceptos básicos, el de "campo", se identifica precisamente con la estructura dinámica del grupo de discusión. (Villafañe, 1999, p. 44)

Se selecciona el grupo de modo que incluya de 6 a 12 personas, con un ambiente cultural común o que tengan experiencias respecto al tema de estudio. Si bien el moderador debe tener un esquema general de la sesión, se aconseja evitar los formatos inflexibles y las secuencias sumamente estructuradas de las preguntas. Esta técnica tiene la ventaja de permitirle al moderador intercambiar con un número mayor de personas y con un pequeñísimo aumento de tiempo. Adicionalmente permite profundizar más allá de las respuestas superficiales. 
Primera sesión. Demanda y primeros contactos con miembros del Consejo de Dirección de Telecubanacán para delimitar los objetivos y alcance de la investigación, formar el equipo asesor, logrando una representatividad de todos los departamentos de la entidad, concertar las próximas entrevistas para negociar con el equipo asesor el esbozo metodológico de la propuesta de estudio y establecer el contrato entre ambas partes respecto a: acceso a la información requerida y colaboración de directivos y trabajadores durante la investigación.

Segunda sesión: Familiarización con el equipo asesor, presentar el proyecto de investigación y desarrollar un conversatorio breve a modo de capacitación en cuanto a los fundamentos básicos de la imagen y la identidad televisiva: importancia de la Imagen Corporativa, la Imagen en Cuba hoy, ejemplificar cómo se hace televisión desde la comunicación, cómo vemos el telecentro pensando en una imagen visual ideal y una exposición técnica breve de términos y elementos que componen la identidad visual (logotipo, slogan, gama cromática, tipografía...)

Tercera sesión: aplicar el Briefing Operativo.

Cuarta sesión: Compartir resultados del Briefing Operativo y formar el equipo de gestión encargado de realizar la propuesta de diseño, integrado por un especialista en comunicación y publicidad, un diseñador y la estudiante de Comunicación Social al frente del proyecto de investigación

Briefing Operativo: Es un cuestionario que operacionaliza acciones en función de la solicitud, o sea, la descripción del encargo que parte de un interés institucional y requiere especificaciones para realizar el trabajo. Sus preguntas están estructuradas en un orden causal e invariable. Por la complejidad que puede presentar debido a los elementos técnicos y profesionales contemplados, debe realizarse particularmente a cada uno de los encuestados. Se considera necesario lograr una representatividad de la organización, por tanto el cuestionario es dirigido a todos los jefes de departamentos de Telecubanacán. Persigue como objetivos caracterizar la identidad visual actual de Telecubanacán e identificar los elementos de identidad visual que contribuyan a formar la imagen deseada por Telecubanacán. 


\section{8. ¿Cómo procesar las informaciones obtenidas?}

Uno de los rasgos distintivos de la investigación cualitativa es la forma en que se analizan los resultados porque esta no es una etapa enmarcada en el fin de la investigación, sino que se realiza de forma progresiva, desde le inicio de la misma, incluso antes de aplicar instrumentos, ya se obtienen resultados con sólo acceder al campo de estudio, lo que permite reformular la investigación y formular otras preguntas con la aparición de nuevas inquietudes. "La epistemología cualitativa define la interpretación como un proceso progresivo, donde la aparición de nuevos indicadores no es el resultado de los datos producidos, sino la incorporación de estos en sistemas cada vez más complejos de interpretación" (González, 1997, p. 35)

Los datos recogidos en el campo constituyen piezas de un puzzle que el analista se encarga de ir encajando, utilizando la evidencia recogida para orientar la búsqueda de nuevas evidencias susceptibles de incorporarse a un esquema emergente de significados que da cuenta de la realidad estudiada y que poco a poco va aproximando al investigador a la descripción y la comprensión de la misma. (Rodríguez, 2004, p. 197)

\section{9. ¿Posee validez y fiabilidad la investigación cualitativa?}

La investigación cualitativa ha sido objeto de múltiples incomprensiones con relación al tema de la validez y fiabilidad, elementos que tributan a la calidad de la investigación. Al hablar del tema se alude al rigor metodológico con que ha sido diseñada y desarrollada, a la confianza que, como consecuencia de ello, se puede tener en la veracidad de los resultados conseguidos. En general, la idea de calidad de la investigación se asocia a la credibilidad del trabajo desarrollado por el investigador. (Rodríguez, 2004, p. 283)

Al utilizar diferentes fuentes y métodos de recolección, se emplea la triangulación de datos para contrastar resultados, análisis de datos en progreso y en el momento que se ofrecen; ejemplificar con los criterios de los informantes, para garantizar la objetividad y la imparcialidad, en definitiva, la credibilidad de los datos. "La triangulación es un procedimiento ampliamente usado que consiste en el uso de diferentes fuentes de datos, investigadores, perspectivas o metodologías para contrastar los datos e interpretaciones. " (Denzin, 1978, citado en Rodríguez, 2004, p. 287).

\section{Resultados}

Cuando se establecen los objetivos de la investigación, cada uno de los pasos de la estrategia metodológica está orientado hacia el interés de obtener resultados que fiscalicen y promuevan la imagen corporativa de Telecubanacán. Crear, empujar fronteras, introducir nuevas maneras de ver y enriquecer el intercambio cotidiano con el televidente constituyen los imperativos durante el estudio, que exponen los siguientes resultados:

Telecubanacán no presenta antecedentes de investigación en comunicación, y consecuentemente no se planean intervenciones conducentes a la realización de 
diagnósticos de los estados existentes, de las necesidades y posibilidades de cambio en el funcionamiento, estructuras, cultura y comportamiento organizacional. Por otra parte, perfilan los estudios predictivos de grupos de discusión, encuestas y entrevistas, para lo cual es vital el apoyo de instituciones políticas, educativas y en general de la población villaclareña.

Aunque en actas de reunión del Consejo de Dirección constan algunas opiniones sobre la importancia del grupo metodológico en el sistema de la comunicación institucional, Telecubanacán no cuenta con un equipo multidisciplinario que se encargue de la planeación y la planificación de un sistema de comunicación, para el cual se han dado algunos pasos como la confección del Expediente de Nueva Estructura con las facultades y funciones de cada departamento, pero aún falta la forma de canalizar la realización de investigaciones de campo que condicionen y sustenten prácticas comunicativas hacia el interior y el exterior del telecentro. Telecubanacán no posee sistema de comunicación, ni siquiera estructura explícitamente programas de comunicación internos, a no ser los espacios de reunión oficiales institucionalmente establecidos.

La organización no posee Manual de Identidad Visual Corporativa, los primeros diseños son empíricos, improvisados, hasta el origen del nombre es ajeno al propio colectivo de trabajadores. Además de que los resultados son injustificados, devienen incompletos y no se respetan elementos básicos del diseño corporativo porque no son adoptados colores únicos, logotipo, slogan, aplicaciones para señalética, rotulado de autos y regulaciones en torno a la proyección a través de los distintos espacios de emisión.

Se aprecia desconocimiento por parte de los trabajadores sobre la identidad visual actual del telecentro. La organización no proyecta símbolos visuales hacia sus públicos. No existen normas de aplicación referidas a los diseños gráficos-visuales. Relacionado con la potenciación de los recursos audiovisuales a emplear en cada programa, está la segmentación de los públicos a que va dirigido, la ubicación en tiempo y espacio, de manera global el balance temático que debe caracterizar un día y una semana de transmisión planificada; la preocupación y el control de este balance no existe. Se dificulta la unión de todas las propuestas en un único discurso televisivo de Telecubanacán, no existe uniformidad, ni homogeneidad. Los trabajadores comparan el telecentro con otros del país y se aprecia incertidumbre ante el deseo de garantizar mayor nivel de aceptación en sus públicos. La situación problémica planteada por Telecubanacán se concreta en elegir contenidos y formas que, dentro de la diversidad, exhiban coherencia y exquisitez, la necesidad de un elemento integrador capaz de hacer común todas sus acciones comunicativas: la identidad visual corporativa.

Se detecta que no está definida la identidad visual del telecentro. La organización no tiene "claro" los elementos visuales a potenciar en el diseño para formar una imagen deseada. Por tanto no se le concede importancia al concebir y planificar estrategias de comunicación a corto, mediano y largo plazo con los diferentes públicos. Según los informantes clave, la imagen que desean formar está basada en su visión de ser un telecentro de proximidad cercano a las prácticas comunitarias y elevar su status y los indicadores de prestigio, reconociéndose como un colectivo profesional, con elevado 
sentido humanístico y revolucionario, respetuoso de las tradiciones culturales y la identidad nacional. Un telecentro provincial en ascenso, con posibilidades de aumento, de crecimiento.

Durante el monitoreo, elemento esencial dentro de la observación participante, se dificulta la unión de todas las propuestas en un único discurso televisivo, no existe univocidad entre las propuestas televisivas que conforman la programación. Por eso la inquietud institucional hacia la proyección de una identidad visual, necesita primeramente de la estructuración y desarrollo de un programa de identidad visual que funcione como elemento integrador en un intento por ser comunes y sinérgicos en todas las acciones comunicativas planificadas. Disponerlo oficialmente para regular y fiscalizar su aplicación coherente, es posible a través de un Manual de Identidad Visual Corporativa para Telecubanacán.

Constituye una preocupación en repetidos planteamientos, el reflejo de la identidad cultural de la provincia a través de cada uno de los programas de Telecubanacán. En espacios de emisión nacional como el pase a la revista informativa de la Televisión cubana "Buenos Días", se necesita potenciar más allá del contenido, otros recursos técnicos y expresivos. Se critica la poca sistematicidad de las acciones de comunicación interna. Es explicitada la necesidad de exigir un alto grado de univocidad para desarrollar un trabajo unitario y coherente, modernizar los mensajes visuales de Telecubanacán, redefinir y repensar el enfoque del medio para lograr standares de calidad superiores.

Dentro de la misión social del telecentro, el fortalecimiento de la programación provincial y el control de la calidad de los trabajos informativos para la televisión nacional constituyen premisas básicas, pero hasta el momento sólo es recurrente cuestionar la producción y técnica de los materiales estableciendo formatos técnicos de calidad. Ahora es posible lograr aciertos notables teniendo presente que la imagen en la televisión posee su sintaxis propia, a la que resulta imprescindible añadir otros recursos técnicos y expresivos. Las expectativas que suscita la TV involucran a la pluralidad expresiva del medio. Los públicos suelen reclamar "otras cosas" en la pantalla, salir de la rutina. De alguna manera proyectan sus deseos, al ritmo de los cambios que exigen para disfrutar con más plenitud del tiempo frente a "la tele". Por ejemplo, de ningún modo se puede ignorar que los jóvenes experimentan una empatía con las tecnologías audiovisuales e informáticas y una expresiva complicidad con sus relatos e imágenes: este público está ávido de otros modos de percepción y de lenguaje en la TV, de otra visualidad cultural, que incluye tanto el entorno tecnológico como el nuevo imaginario.

El villaclareño, como el cubano, es un televidente asiduo, reclama emoción, convencimiento, verdad, productos nacionales, aunque disfrute con algunos enlatados. Una obra de arte audiovisual puede entretener, instruir, estimular la imaginación y contribuir a la formación de criterios. Las propuestas pueden ser más eficaces, si no guardan distancia del consumo cultural, del estudio de los segmentos de población. La referencia constante a pensar el público de Telecubanacán como la población en general, es un síntoma de la carencia de una segmentación inteligente. 
Merecen un mayor análisis las jerarquías que establece el diseño de programación, distante en algunas ocasiones de la práctica sociocultural, de cómo se perciben y de cómo se recepcionan los productos, la importancia de los espacios claves para la comprensión de los comportamientos sociales. Otro concepto que se subestima es la relación de hábito que establecen públicos y programas, los cambios de días y horarios, sin explicación, dislocan o cortan esa relación. Tales complejidades involucran la relación entre cultura, sociedad y heterogeneidad en el momento de repensar y redefinir el enfoque del medio televisual, teniendo en cuenta su papel estratégico e incidencia en la cultura cotidiana de la mayoría de las personas.

La televisión utiliza movimiento y acción para crear impacto. Utiliza historias para entretener y para llegar al punto deseado. En televisión las demostraciones son persuasivas porque se cree lo que se ve. La imagen y el sonido deben reforzarse entre sí. Más que ningún otro medio, la televisión tiene la capacidad de tocar las emociones, de impulsar a la gente a que experimente sentimientos. Esta habilidad de tocar los sentimientos de los televidentes, hace que los programas de televisión sean entretenidos, divertidos, absorbentes. Las situaciones de la vida real con todo su humor, coraje, miedo, orgullo, celos y amor toman vida en la pantalla.

El dominio de la sintaxis, o sea, el cómo se dice, descuella en un espectáculo televisual desembarazado del excesivo lenguaje verbalista. El cómo narrar involucra un conjunto de recursos técnicos y expresivos, entre los que se encuentran la dramaturgia, el sonido, la fotografía, la escenografía, y entre todos ellos, un elemento integrador que los hace comunes, sinérgicos y coherentes en el logro de la eficacia del mensaje, la identidad.

La realidad de los resultados de esta investigación supera todo tipo de ficción, desde la acción conjunta de un equipo de trabajo se va al encuentro de expectativas, modelos, valores y comportamiento, discrepancias en cuanto a lo atrasado y lo moderno, lo interesante y lo aburrido, lo coherente $o$ atractivo. Los nombres de las organizaciones, las formas, las tipografías empleadas y los colores son elementos muy atractivos al gusto de las personas, pero dichos elementos tienen valores o significados que deben responder a la esencia de Telecubanacán, ellos por sí solos no constituyen su identidad.

El color es un elemento identificador y personalizador fundamental en una identidad visual. Para las propuestas de logotipo y presentaciones audiovisuales de Telecubanacán, desde el inicio se piensa en el blanco, este se asocia a la luz, la pureza, se considera el color de la perfección, significa seguridad y limpieza; a diferencia del negro, por lo general, tiene una connotación positiva, puede representar un punto de partida afortunado. Se escoge también el gris que significa estabilidad, su uso inspira la creatividad y simboliza el éxito, a la misma vez transmite una sensación de frescura y es el centro de todo; simbólicamente, el blanco y el negro con sus degradaciones de gris, son el color de la lógica y de lo esencial. Todo esto es coherente con las ideas sugeridas de los trabajadores del telecentro. Se empiezan a trabajar los colores primarios luces utilizados por la televisión: rojo, azul y verde, y en un intento de ser coherentes con el Manual de identidad Visual Corporativa de la Dirección Nacional de Telecentros. 
Resultan seis propuestas para el logotipo, en las dos primeras se recrean formas análogas a la pantalla de un televisor, dispuestas de diferentes formas, pero en cada uno de los casos ubicadas debajo del nombre Telecubanacán en la parte inferior central, atribuido a la referencia del centro de Cuba.

En la primera propuesta, de manera horizontal consecutivamente, representando los tres colores mencionados y con la impresión de la abreviatura del nombre Telecubanacán (TLC) en blanco igual que el genérico.

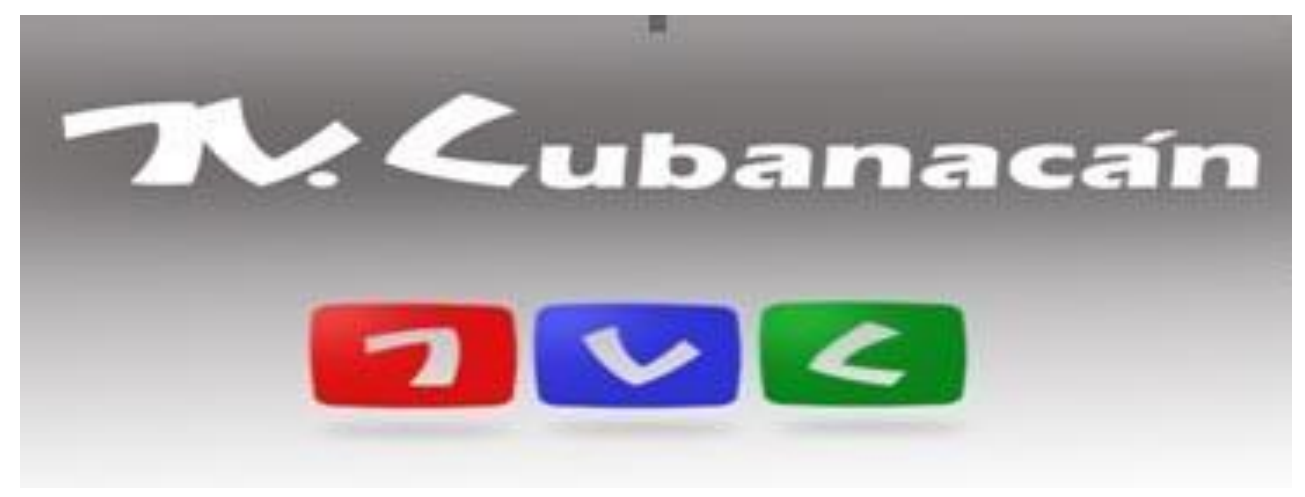

En el segundo caso se agrega otra figura, pero en negro con la terminación de tres puntas de una estrella blanca, representando la boina de Che Guerrillero, símbolo de la provincia e idea recurrente en el discurso de los trabajadores; se disponen cuadriculadamente semejando una pantalla aún más grande, el nombre continúa apareciendo en la parte superior en blanco aunque cambia el tipo de letra.

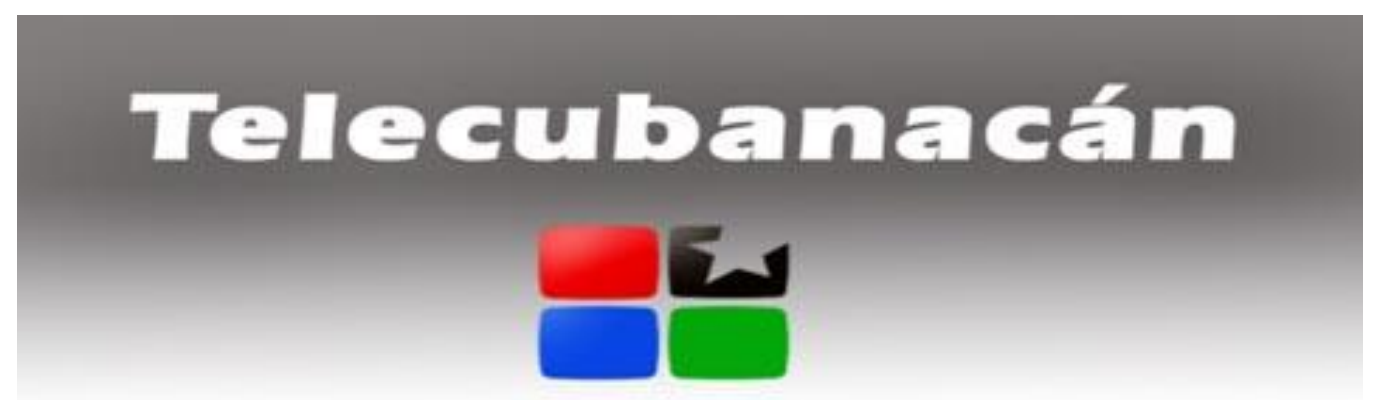

La tercera propuesta juega con la tipografía empleada en el nombre, coloreando de azul el fragmento -cuba- y un triángulo rojo con la estrella solitaria de la bandera fue logrado a partir de la a final. 


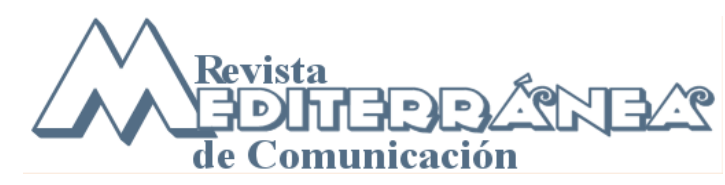

\section{Telecubsuncin}

La cuarta propuesta basa su diseño en el cambio de la tipografía para recrear nuevamente con la vocal -a- otra forma en el centro con el uso de los colores rojo, verde y azul, pero esta vez ubicadas triangularmente apuntando hacia arriba, en correspondencia con el ascenso en las metas trazadas por la organización.

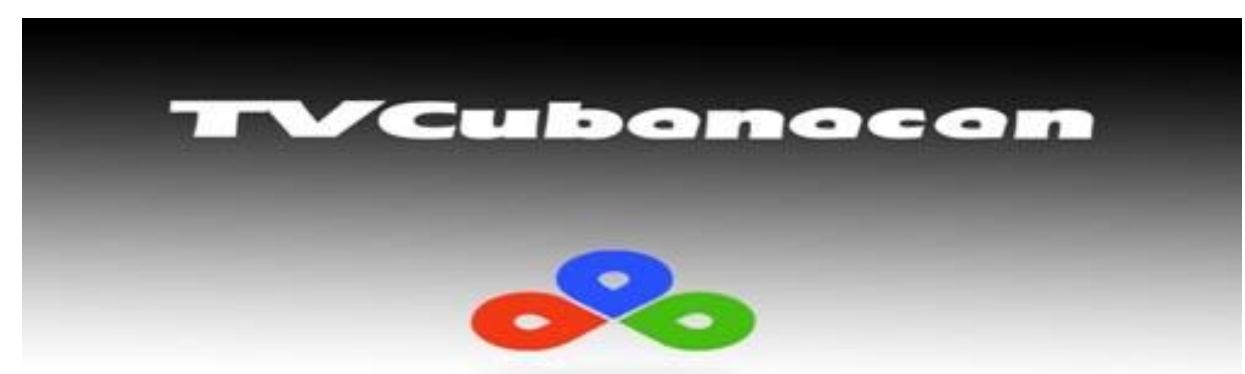

Según los expertos, hasta el momento los resultados no se caracterizan por la sencillez, sino por una simplicidad y pobreza en los mensajes y recursos empleados. Las propuestas logradas carecen de creatividad, es recurrente el uso de los colores generalizados en la televisión como el rojo, verde y azul; tampoco se logra un impacto. Hasta el momento se trata sólo de un telecentro, pero tiene que ser además, el de los villaclareños.

La quinta propuesta, igualmente, emplea la tipografía del nombre Telecubanacán como pretexto para formar, esta vez, la síntesis del público, un grupo de tres personas que sonríen complacidos frente a la pantalla de su televisor. En esta propuesta se utiliza junto al gris, el naranja que combina la energía del rojo con la felicidad del amarillo, este color se asocia a la alegría, representa el entusiasmo, la atracción, la creatividad, la determinación, el éxito, el ánimo y el estímulo porque la visión del color naranja produce la sensación de mayor aporte de oxígeno al cerebro, produciendo un efecto vigorizante y de estimulación de la actividad mental. En heráldica el naranja representa la fortaleza y la resistencia, que tiene que ver con la estabilidad; posee una fuerza activa, radiante y expansiva, un carácter acogedor, cálido y una cualidad dinámica, muy positiva y energética. Además tiene una visibilidad muy alta, por lo que es muy útil para captar la atención y es uno de los colores de máxima agudeza visual en la televisión. 


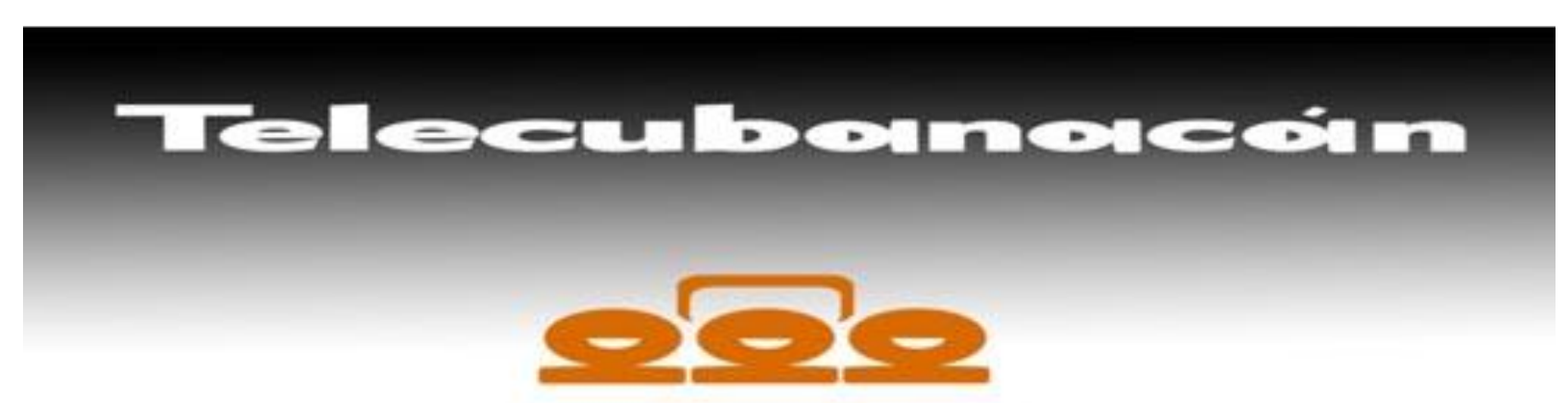

Este color es sugerido por los trabajadores del telecentro debido a la connotación, desde el punto de vista comunitario, del equipo de béisbol de la provincia. Aunque el naranja no se justifica por características naturales, geográficas o económicas de la provincia, se ha arraigado popularmente debido a la afición y pasión de sus pobladores. Además es igualmente significativa la identificación del telecentro con la cobertura especial realizada durante la 48 y la 49 Serie Nacional de Béisbol ante el pronóstico de un "año naranja" y la coronación del equipo Subcampeón de ambas. En la última ocasión, sobre todo, la efervescencia popular fue tal que trascendió las fronteras provinciales hasta contagiar todo el país; y el papel asumido por los medios de comunicación, otorgando más protagonismo al acontecimiento, arraigó determinados rasgos identitarios de la provincia que sobresalen en el culto popular masivo: el epíteto de la Ciudad Naranja llega para quedarse por un buen tiempo, bien recibido además por sus pobladores que merecieron la categoría de mejor afición del país porque con pasión, alegría y creatividad apoyaron espontánea y respetuosamente con numerosas iniciativas.

Cada una de las propuestas realizadas es presentada al equipo asesor, previamente evaluadas por los expertos y el grupo de diseñadores de la ACCS seleccionados con el propósito de contar con otras valoraciones además de las del grupo de gestión para defender una u otra alternativa. El proceso de creación transita por varias etapas de manera ascendente, las propuestas son el resultado de una evolución global, consideraciones interdisciplinarias y opiniones conjuntas.

Se considera más completa la propuesta seis, en esta decisión coinciden las opiniones de expertos, informantes, grupo de gestión y los intereses de la dirección del telecentro. Para su diseño, se emplea la gama cromática resultante de los casos anteriores: el gris, el blanco de fondo y el naranja, acogió también la mascota beisbolera, una naranja que picada a la mitad se convierte en la síntesis de una antena parabólica. A continuación de la antena, el nombre Telecubanacán, resultado de la transmisión a través de los distintos subterfugios electrónicos, pero jugo también de esa naranja porque forma parte de la identidad del villaclareño, además ¿a quién no le gusta la naranja?, es dulce, fresca, saludable, agradable, deseada, saboreada por todos. Según la disposición del nombre, Telecubanacán puede ser entendido como la otra mitad de esa naranja, simboliza la otra afición y pasión de los villaclareños además de la pelota. La tipografía usada para el nombre es fuerte, firme, clara, legible. La composición mantiene una relación de equilibrio expresada en el arreglo de los elementos para obtener una distribución agradable, se logra una unidad de pensamiento, de presentación y diseño. 

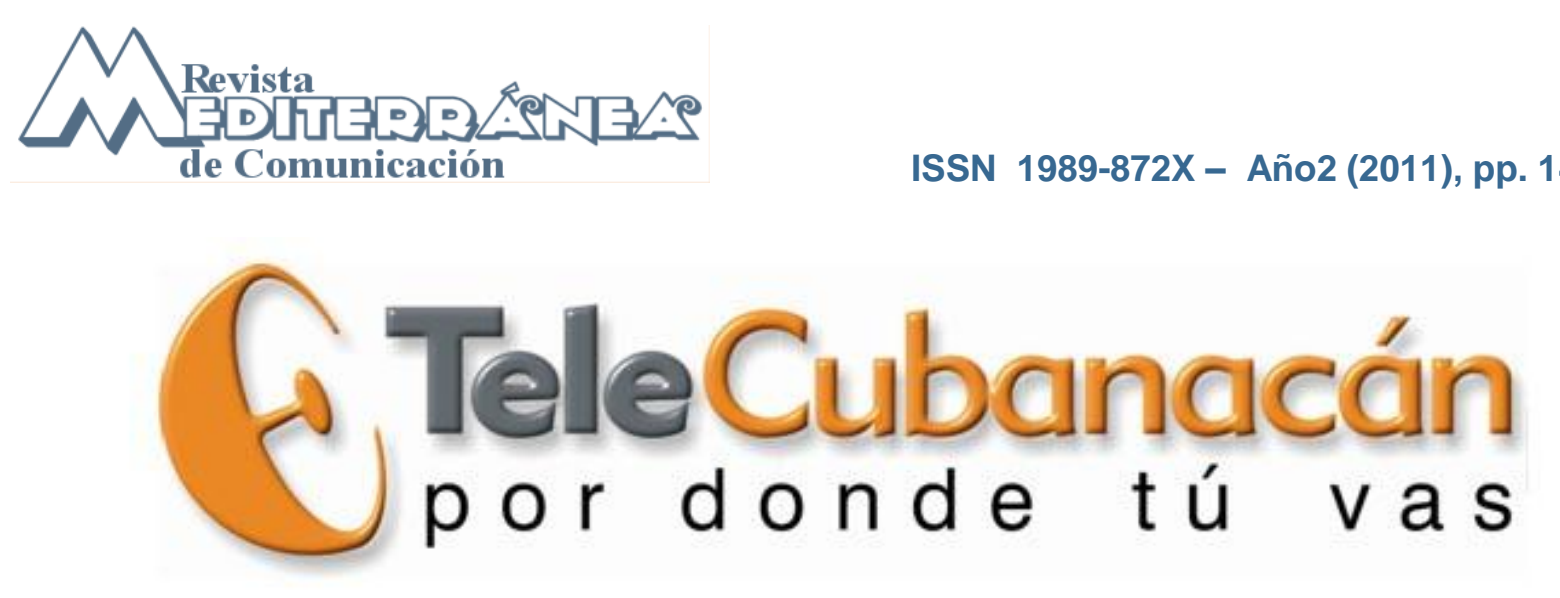

El slogan está en la parte inferior del nombre en letra minúscula, con una tipografía diferente, menos destacada, pero igualmente legible. "seguimos siempre el camino" y "por donde tú vas", son dos propuestas, fragmentos del tema "Son los sueños todavía", del cantautor cubano Gerardo Alfonso, dedicada al Guerrillero Heroico, una forma de simbolizar la presencia del legado guevariano. La seleccionada, "por donde tú vas", es una frase corta, requisito indispensable para ser memorizada y repetida. Además supone una cercanía a las personas, lo popular, lo barrial, regional y comunitario, el hecho de que Telecubanacán sea el reflejo de la realidad villaclareña, la imagen de los pobladores en su cotidianidad: en los hogares, centros de estudio, de trabajo, en las calles y otras instituciones públicas, refuerza la idea de que se le identifique como el telecentro de los villaclareños. Por donde tú vas es también una frase convocatoria, de compromiso, establece una continuidad de espíritu revolucionario, respeto a los principios e ideales patrios y defensa de la identidad nacional. Impone también un reto al telecentro dando el valor que merece al televidente con derecho de verse reflejado en la pantalla y la idea de ir sugiere constante movimiento, camino por transitar, nuevas cosas por hacer, experiencias por descubrir, metas por alcanzar, cambio, novedad, coherentes con la visión de Telecubanacán.

Se considera que debe acompañar al telecentro una representación musical guevariana con motivo de evitar el uso de las fotos, que rompen con la idea de logotipo, teniendo en cuenta además el respeto de los derechos de autor, hasta el momento subestimados con la presentación anterior. Son escogidos dos temas: "Che comandante", de Carlos Puebla y "Son los sueños todavía", de Gerardo Alfonso; su popularidad en Cuba y en otras partes del mundo facilita la rápida asociación y el reconocimiento de la letra, la melodía. Por eso es efectivo el arreglo musical de la presentación y la selección del fragmento para el slogan. Resultan cinco propuestas con una duración de diez segundos aproximadamente, en todas se emplean ritmos cubanos para mantener siempre la identidad nacional, nada de ritmos foráneos, sí latinoamericanos por los lazos históricos que unen al Che con Cuba y el resto del continente. El resultado es una composición contagiosa, bien arriba, con ritmo televisivo, de convocatoria, sobre todo en la presentación de las transmisiones. Las cortinillas de la programación y el encadenamiento se escogen luego y, específicamente para el inicio y final de las transmisiones, se utiliza un tema original del compositor villaclareño que colabora en el proyecto.

Para la presentación oficial, ya definidos colores, logotipo, slogan y música las propuestas son más precisas. En las dos propuestas el diseño es concebido a partir de la forma redonda recreada de la naranja, mascota beisbolera a la cual se debe el color usado. Una 
elipse es la síntesis de la antena parabólica a través de la cual es posible la transmisión televisiva y es también un recurso expresivo en la imagen del imagotipo o identificador. El círculo es símbolo de la unidad, completitud, la perfección; y psicológicamente, redondez es posibilidad, aumento, crecimiento. Ambas son valoradas por los expertos e informantes seleccionados y merecen la aceptación del quipo de gestión, la decisión por la segunda propuesta corresponde a la dirección del telecentro.

La primera propuesta se diseña sobre un fondo de esferas blancas, que van girando y coloreándose naranja. Tomar otro color implica cambio, novedad, puertas que se abren (apertura), antes de espalda y ahora de frente a la realidad, a un nuevo tiempo, despertar, añoranzas. Va dibujándose con el nuevo color la antena parabólica de manera plana hasta lograr una imagen tridimensional y se convierte girando (idea de movimiento) en la naranja que luego da lugar al logo, el nombre con acento en forma de estrella que gira muy rápido hasta colocarse sobre la -a-. Debajo el slogan, la razón de ser y misión del telecentro.

La otra propuesta: en un fondo blanco, con una expresión de vacío, repentinamente aparecen las esferas naranjas y se dirigen hacia el televidente a modo de convocatoria, buscan un acercamiento, cierta complicidad. Lo colorean todo de naranja, (ahora empieza a ser diferente, todo tiene otro color, deseos, entusiasmo, alegría). El color naranja pasa a ser el fondo de una construcción que se va edificando tridimensionalmente y siempre de manera ascendente a partir de muchas esferas blancas, que representan todo el pueblo de Villa Clara, sus tradiciones, su pasión, su afición por el béisbol. Estos son los materiales de la obra y la fuerza de trabajo, que inspirada por la figura de Che, necesita confiar en el futuro. La imagen de Che simbolizada es apenas una síntesis de la estatua de José Delarra con el reflejo de una estrella solitaria que alcanza las dimensiones de esta obra plástica del artista cubano, ubicada en el Conjunto Escultórico que guarda los restos mortales del Guerrillero y sus compañeros de lucha, plaza de todos los cubanos y visitantes extranjeros de paso por la provincia (otro elemento identitario de Villa Clara a potenciar). El diseño en su conjunto es sencillo sugiriendo la propia sencillez defendida por los trabajadores de Telecubanacán. La unidad, premisa en el discurso de muchos, es reflejada en la unión de todas las esferas durante la construcción y hasta el final con el logro del propósito que descuella en el logotipo (su identidad, estilo, marca) y la frase comprometida: por donde tú vas.

Se propone un corto de ejemplo para futuros separadores de programas en las transmisiones diarias. Consiste en el trabajo simbólico con formas planas y redondas, blancas y naranjas en un fondo blanco. De izquierda a derecha, se van presentando cual protagonistas del espectáculo en un escenario a telón abierto. De acuerdo a sus dimensiones se agrupan unas al lado de las otras, arriba o abajo, y finalmente, la superposición que coincide con la síntesis de la antena de transmisión da lugar al logotipo y slogan de Telecubanacán. Acompaña a la propuesta visual un ritmo musical bien arriba que presenta cada uno de los componentes del diseño y sugiere transición. El conjunto es sencillo e instantáneo, su función es enlazar una propuesta televisiva con otra, recordando al televidente que está viendo Telecubanacán, el telecentro de los villaclareños. 
Para el inicio y cierre de las transmisiones es necesaria una imagen de encadenamiento que anuncie el inicio o fin de las transmisiones. Del logotipo, ubicado en la parte superior, caen consecutivamente una tras otra esferas naranjas y en diferentes posiciones cada vez sobre el anuncio de inicio o fin de las transmisiones. Para lograr un efecto lúdico el peso de las esferas al caer sucesivamente hace que la información baje al compás de la música, sonsoneando (propio título de la composición), en otro momento la caída de unas sobre otras hacen del anuncio una balanza que se inclina hacia un lado o hacia otro hasta deslizarlas; desaparecen y luego se reinicia el ciclo pero nunca idénticamente. Se intencionó el entretenimiento, manteniendo la expectativa con la caída de las esferas siempre diferente la próxima vez, se explotó el elemento lúdico, el juego es siempre un recurso eficaz para cualquier edad o género. Este constituye un momento de reposo, de transición para la persona que se encuentra frente a la pantalla y es espectador de las propuestas de Tele Rebelde (frecuencia por la que transmite Telecubanacán). La composición original de uno de los músicos villaclareños, colaborador en el proyecto, acompaña el diseño. Se trata de un Son, ritmo cubano por excelencia, su melodía evita un cambio brusco, en tanto deviene en ritmo suave, cual pausa que implica serenidad, tranquilidad y sugiere transición. Por regla general se necesita una pareja para poder bailar un Son cubano, así como se necesita del televidente para hacer televisión, aunque desconocido, anónimo, multitudinario, no se puede negar el rol activo que pueden asumir como consumidor de televisión; una vez más la razón de ser del telecentro completa la intención del mensaje.

Además de tributar información para el sistema informativo de la Televisión Cubana a través de reportajes periodísticos publicados en las diferentes redes informativas, Telecubanacán realiza pases en vivo a la revista matutina "Buenos días". Siendo estos, vías de comunicación a través de las cuales se le puede identificar como el telecentro de los villaclareños. Pensando en esto, se propuso un diseño de presentación y una escenografía para recorte. Coherente con el horario, la propuesta consiste en la recreación de un amanecer, veleta en movimiento (por las nuevas brisas que corren) ubica las coordenadas con la figura del gallo mañanero, prima el color naranja en un paisaje villaclareño con collage de tejados y azoteas, sobresale el Hotel Santa Clara Libre, edificio insigne de la historia de la provincia y lugar de descanso para visitantes. Despunta el sol en el horizonte, una esfera naranja sube hasta tornarse el fondo blanco, en el que confluyen rápidamente otras esferas naranjas de iguales dimensiones pero con imágenes de sitios representativos de la provincia, escenarios sociales de interés político, económico, artístico y deportivo para los reportes noticiosos. La presentación es dinámica como lo es el acontecer noticioso, el choque es sucesivo entre las esferas, cambian las imágenes una y otra vez hasta dar lugar al logotipo y se sustituye, pertinentemente, el slogan por: para buenos días.

Si bien cada programa de la parrilla del telecentro basa su diseño escenográfico, de luces, de fotografía, de vestuario en sus ejes temáticos. El Noticiero constituye el eje central de la programación, sobre todo, si predomina dentro de su misión y principios, la información. Es un espacio formal, serio, importante e integrador porque confluyen todos los ámbitos de la cultura de un territorio: la política, la economía, las artes, el deporte. Adquiere una connotación de respeto y compromiso con la información, con cada uno de los datos que 
se ofrecen, e implica una serie de actuaciones y comportamientos sociales positivos o negativos, en cada uno de los casos la población es protagonista y se ve reflejada en la pantalla. Por eso el nuevo diseño para Noticentro de Telecubanacán descansa en los presupuestos definidos y pautados en el Manual de Identidad Visual Corporativa. La rapidez, inmediatez y fuerza de la noticia, caracterizan la propuesta de presentación para Noticentro. Son simbolizadas a través de iconos cada una de las esferas de la vida social del territorio, utilizando como soporte la imagen redonda pero plana, esta vez, y de color naranja. Una gran masa forma filas, inmediatamente que aparece, en gris y naranja, el nombre del espacio informativo. Cada uno de los símbolos representados con un diseño apenas dibujado, sencillo, en forma de síntesis, se muestra en la medida que dan vuelta las figuras redondas de color naranja pero dorado con la intención de producir sensación de prestigio, el dorado significa sabiduría, claridad de ideas, riqueza y con frecuencia representa alta calidad. En constante movimiento los círculos se detienen simulando una red bien apretada, una colmena, sinónimo de unidad, laboriosidad y empeño, en medio de la cual aparece el nombre: Noticentro.

La página Web del telecentro es un canal de comunicación que trasciende las fronteras cubanas. Motivo para renovar el diseño del banner contentivo de ejes temáticos generales, fijos, y otros temporales, los que se regulan por el Manual. Existe un banner general temático que cambia según fechas históricas, conmemoraciones patrióticas, acontecimientos de la provincia y hasta el país, algunos ejemplos son: La Jornada Camilo-Che y la 49 Serie Nacional de Béisbol. Las temáticas permanentes son las reflexiones del compañero Fidel, los bloggers, las noticias relacionadas con el bloqueo, las galerías de imágenes, los cinco héroes, video secuencia y video en línea. Se emplean símbolos representados con un diseño apenas dibujado, sencillo, en forma de síntesis, trabajados en la gama cromática pautada en el Manual.

La televisión exige requerimientos especiales en cuanto a comunicación porque televisión es comunicación en sí. Tal vez otras organizaciones, empresas, entidades de producción o servicio puedan regular, incluso, crear con mayor facilidad, economía y propósitos su identidad visual; esta nunca va a adquirir un carácter masivo. El fenómeno de la identidad visual en la televisión adquiere por sí solo un carácter masivo y global, por lo que entre las exigencias de su identidad visual incorpora a su Manual otras modalidades de expresión visual, no comprendidas usualmente. Son necesarias, pues, aplicaciones específicas a la TV para fiscalizar el diseño de la identidad visual a través de la programación.

El Máster o control maestro es el lugar desde el cual, un equipo de realización, de producción y técnica hace posible la salida al aire de la imagen de Telecubanacán, y el realizador, como director de orquesta, tiene a su disposición un conjunto de herramientas para lograrlo. El suicher está compuesto por un banco de efectos o wipe, el recortador de imagen, el banco de preview y el banco de programa. El banco de efectos brinda la posibilidad de enriquecer la transmisión insertando cualquier efecto que se desee, seleccionando previamente entre qué señal se hará.

En la televisión se utiliza la mezcla por yuxtaposición, teniendo en cuenta que el ojo humano tiende a mezclar pequeñas unidades de color que se encuentran muy próximas 
entre sí. En estudios realizados se ha comprobado que el ojo puede percibir las características de los colores en una imagen que está en la zona de máxima agudeza visual, o sea, entre los amarillos verdosos y naranjas al rojo. En esta zona de máxima agudeza visual sólo se percibe el matiz o tinte de la imagen sin percibir ninguna otra característica del color como el brillo y la intensidad.

Para el uso del recortador de imagen o croma key, además de cuidar que la escenografía está pintada totalmente de azul y sea lo más uniforme posible desde todos los ángulos de la cámara, que la intensidad de la luz sea la misma en toda el área del recorte, el color adecuado para el vestuario del locutor debe estar cerca de la zona de los carmelitas, naranjas y rojos, o sea, todos los contrarios al azul.

Si se utilizan múltiples colores puros o colores altamente saturados en la imagen televisiva, el ojo humano tiene que reenfocar constantemente, causándole fatiga. Para escenografías sin uso del recortador es muy recomendado el blanco, evitando profundidades y dando valor a la luz, se buscan contrastes con pequeñas franjas de otros colores artísticamente logradas y con el apoyo fundamental de las luces. En los momentos actuales Telecubanacán no cuenta con la infraestructura necesaria para potenciar esta tendencia moderna por lo que debe recurrir al buen uso de los colores en la propia escenografía, sin dejar nada a las luces.

Dentro de los colores corporativos del telecentro, el uso de la gama cromática naranja en las escenografías de los programas transmitidos por el telecentro, en primer caso, cumple con los parámetros técnicos que posibilitan el recorte, siendo totalmente opuesto al azul.

Del logotipo, el imagotipo o identificador debe aparecer en la parte superior derecha de la pantalla durante la transmisión. Esta posición permite su visibilidad y la no interferencia de las infocintas que pueden correr con mensajes durante la salida al aire. Otra alternativa es la parte inferior derecha de la pantalla para lo que se debe tener en cuenta reducir el espacio a las infocintas. La función del control maestro que lo permite es el recortador sobre los colores primarios luces de la televisión (rojo, verde y azul), preferiblemente sobre un fondo azul. El color naranja del identificador del telecentro posibilita un buen recorte de la imagen sin distorsiones por ser totalmente opuesto al azul, de lo contrario sería barrido quedando sólo una silueta transparente.

En el proceso creativo se utilizan varios programas computacionales de diseño gráficovisual. El Corel Draw es útil para dibujar, el Adobe Photoshop y el Adobe llustrador para trabajar las características de los colores, el 3ds Max brinda la posibilidad de diseñar en tres dimensiones, el Particle llusion ayuda con los efectos, el Alter Efects es necesario para el trabajo con los efectos de video de corta duración, junto al Macromedia Flash aunque con menos posibilidades. Para los ajustes del arreglo musical a la presentación se utiliza el Avid.

El Manual de Identidad Visual de Telecubanacán se elabora en el Adobe Reader. Lo compone en primer lugar el Manual de Marca, donde se describe el proceso de construcción del imagotipo o identificador con las áreas mínimas de invasión, es 
declarada la gama cromática de los colores institucionales, se ofrecen posibles versiones del identificador, la tipografía institucional es pautada, y se señalan las prohibiciones del uso indiscriminado de cada uno de estos componentes. En segundo lugar, el Manual de Aplicaciones, que ofrece gráfica de apoyo al logotipo y constituye las estructuras formales de base para las aplicaciones en distintos soportes, como la papelería: papel y sobre timbrado para cartas y documentos, carpeta institucional, tarjetas de presentación y pases; presenta la señalética interior, y muestra las especificaciones para el Control Maestro que fiscalizan la proyección de la identidad visual del telecentro a través de la programación, con la presencia del identificador en la pantalla durante la transmisión. Por último son propuestos en algunos recursos promocionales y las aplicaciones gráficas al parque móvil del telecentro.

El esfuerzo por normativizar en un Manual de Identidad Visual Corporativa la esencia de Telecubanacán, significa una primera acción a coordinar e integrar con el resto de las acciones de la organización, para intervenir posteriormente sobre la imagen corporativa, de forma tangible y programada. La estructuración de la identidad visual del telecentro villaclareño constituye el primer paso de un proyecto organizacional más ambicioso que han considerado en el propósito de hacer valer una imagen intencional entre sus públicos, pretendiendo inducir una imagen positiva. Cuando los mensajes se adaptan permanentemente a los cambios y prevalecen los puntos fuertes, las repercusiones son equivalentes a un posicionamiento estratégico.

Se puede informar, entretener, instruir, estimular la imaginación y contribuir a la formación de criterios, siendo eficaces y más eficientes al acortar distancias del consumo cultural, del estudio de los segmentos de población y las jerarquías que establece el diseño de programación, analizando la práctica sobre cómo se perciben y se recepcionan los productos comunicativos. En su visión de repensar y redefinir el enfoque del medio para ser un telecentro de proximidad cercano a las prácticas comunitarias y elevar el status y los indicadores de prestigio, reconociéndose como un colectivo profesional; Telecubanacán debe potenciar aquellos que son puntos fuertes en sus recursos humanos, medios tecnológicos y financieros.

La identidad visual del telecentro provincial "Telecubanacán" se convierte pues en el elemento integrador que los hace comunes, sinérgicos y coherentes en el logro de la eficacia de sus mensajes. Esto debe incentivar el talento en beneficio de la planificación de estrategias que a largo o corto plazo, conciban con agudeza, inteligencia, habilidad y creatividad la manera de hacer televisión desde la comunicación.

\section{Conclusiones}

El telecentro villaclareño "Telecubanacán" no proyectaba hacia sus públicos símbolos que tipificaran su imagen visual.

En el momento inicial de la investigación, la identidad visual de Telecubanacán se caracterizaba por la ausencia de: diagnósticos y auditorías precedentes, Manual de 


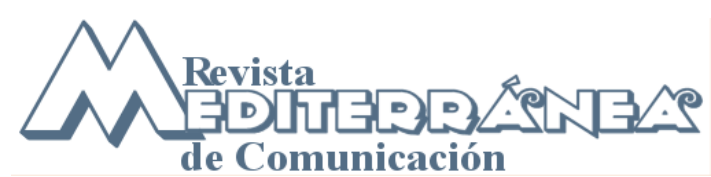

Identidad Visual Corporativa, logotipo, imagotipo o identificador, gama cromática, slogan, tipografía, señalética y aplicaciones en la gráfica, en papelería y en rotulado de autos.

La imagen que desea hacer valer Telecubanacán está basada en su visión de ser un telecentro de proximidad cercano a las prácticas comunitarias y elevar su status y los indicadores de prestigio, reconociéndose como un colectivo profesional.

Se elaboró el Manual de Identidad Visual Corporativa para el telecentro provincial "Telecubanacán". Consta de un Manual de Marca y un Manual de Aplicaciones.

Se propuso la aplicación de la nueva identidad visual a distintos espacios de emisión y elementos susceptibles de uso comunicativo por parte de Telecubanacán: imagen de encadenamiento, presentación, separadores, Noticentro, Pase a "Buenos Días" y Página Web.

Se propuso la disposición de las aplicaciones visuales en la arquitectura de la organización como el conjunto de las señaléticas interiores.

\section{Recomendaciones}

Implementar el Manual de Identidad Visual Corporativa para la gestión eficiente de la comunicación del telecentro provincial "Telecubanacán".

Fiscalizar la proyección de la identidad visual a través de los distintos espacios de emisión de Telecubanacán.

Establecer como una línea de investigación, el estudio de la identidad e imagen en los medios masivos de comunicación, porque como soportes de comunicación en sí, existe una cercanía entre la imagen interna y pública debido al fenómeno particular de percepción masiva.

\section{Referencias Bibliográficas}

Alonso, M. M. y. Saladrigas, H. (2001). Teoría de la Comunicación. Apuntes. La Habana: Editorial Pablo de la Torriente.

Alonso, O. y Bendoyro, P. [s.f]. La imagen organizacional. Una experiencia en su exploración desde un enfoque cualitativo. Tesis de licenciatura no publicada. Santa Clara, Universidad Central "Marta Abreu" de las Villas.

Arrom, J.J. (2008). El nombre de Cuba: sus vicisitudes y su primitivo significado, en Perfiles de la cultura cubana (enero-abril).

Autores Varios. [s.f]. En torno a la televisión. La Habana: Editorial Pablo de la Torriente.

Álvarez, A. M. (2007) La imagen Corporativa. La Habana: Editorial Félix Varela. 


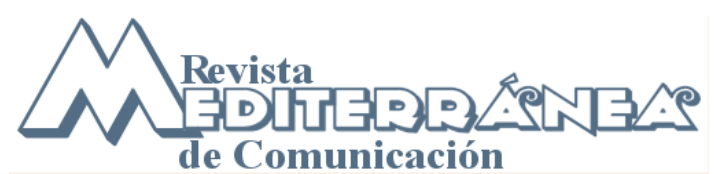

ISSN 1989-872X - Año2 (2011), pp. 140-170

Álvarez, T. y Caballero, M. (1997). Vendedores de imagen. Los retos de los nuevos gabinetes de comunicación. Barcelona: Ediciones Paidós.

Álvarez, D. Y. (2000). Imagen Corporativa. Teoría y práctica desde un enfoque psicológico. La Habana: Editorial de Ciencias Sociales.

Baños, M. (2001). Creatividad y publicidad. Madrid: Ediciones del Laberinto.

Barthes, R. (1990). El mensaje publicitario. La aventura semiológica. Barcelona: Paidós.

Benavides, J. (1998). Lenguaje publicitario. Hacia un estudio del lenguaje de los medios. Madrid: Síntesis S. A.

Boleo, A. P. (1988). Comunicación publicitaria. México: Editorial Trillas.

Bonilla, C. (1997). La comunicación. Función básica de las Relaciones Públicas. México: Editorial Trillas.

Bourdier, P. (1991). Sobre la televisión. Barcelona: Anagrama.

Brull, M. (2006). Modelo de Auditoría de Identidad e Imagen para las universidades cubanas. Una propuesta desde la perspectiva de la Universidad de Oriente. Tesis presentada en opción al grado científico de Doctor en Ciencias de la Comunicación Social. Santiago de Cuba, Universidad de oriente.

Capritotti, P. (1999). Planificación estratégica de la imagen corporativa. Barcelona: Ariel.

Costa, J. (1989). Imagen Global. Evolución del diseño de la identidad. Barcelona: Ediciones CEAC.

Costa, J. (1992). Imagen pública. Una ingeniería social. Madrid: Fundesco.

Costa, J. (2001). Imagen Corporativa en el siglo XXI. Buenos Aires: La Crujía.

Costa, J. (2006). Conferencia en el Tecnológico de Monterrey: Identidad e Imagen. La Identidad Televisiva en 4D. Campus Estado de México. México.

Chaves, N. (1994). La Imagen Corporativa. Teoría y metodología de la identificación institucional. Barcelona: Editorial Gustavo Gili. S. A.

Chaves, N. y Belluccia, R. (2003). La marca corporativa: gestión y diseño de símbolo y logotipos. (1. ed.) Buenos Aires: Paidós.

De la Torre, C. (2001). Identidad e identidades. Aplicación del concepto al análisis de diversos objetos de estudio. Trabajo presentado en el Taller de Estudios de Familia del 


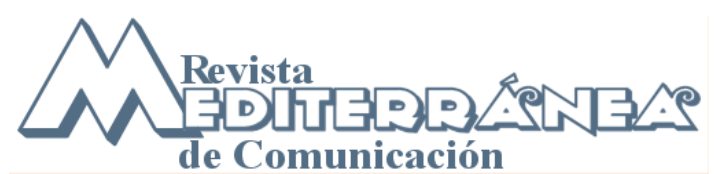

ISSN 1989-872X - Año2 (2011), pp. 140-170

Centro de Investigación y Desarrollo de la Cultura Cubana "Juan Marinello", Febrero, La Habana, Cuba.

Díaz-Guzmán, K. (2008). Criterio de expertos. Conferencia en la UCLV, inédito, 11 de diciembre.

Díaz-Guzmán, K. (2008). Publicidad, Comunicación y Estrategias para comunicadores sociales. México: Editorial Crucet \& Asociados.

Eco, H. (1998). ¿Cómo se hace una tesis? Barcelona: Editorial Gedisa.

El periódico de la publicidad, semanario de publicidad, marketing y comunicación. 2007/2008. suplemento especial.

Expediente de nueva estructura de Telecubanacán. (2009)

Fombrun, Ch. (1996). Reputation. Realizing Value from the Corporate Image. Boston: Harvard Business School Press.

González, E. (2008). Diagnóstico de Imagen Interna Casa Matriz. GEE Palmares. Tesis de Licenciatura no publicada. Ciudad de la Habana, Universidad de La Habana.

González, V. (1989). Profesión: comunicador. La Habana: Editorial Pablo de la Torriente.

González, V. (1997). Para entender la televisión. La Habana: Editorial Pablo de la Torriente.

González, F. (1997). Epistemología cualitativa y subjetividad. La Habana: Editorial Pueblo y Educación.

Gumucio, D. A. (2004). La televisión comunitaria y su papel en la construcción del tejido social. II Foro Nacional de Televisión Comunitaria. Medellín.

Losada, C. (2002). Los medios de comunicación como generadores de imagen corporativa: los públicos internos. Comunicación y Sociedad, 14, (2), 95-113.

Martín-Barbero, J. (1998). De los medios a las mediaciones. Barcelona: Gustavo Gili.

Martín, M. y otros. (2002). Teoría de la comunicación. Epistemología y Análisis de la referencia. La Habana: Editorial Pablo de la Torriente.

Pérez, D. (2007). Estrategia de comunicación, Dirección de Televisión Universitaria de la Universidad de Ciencias Informáticas. Tesis de licenciatura. La Habana, Universidad de La Habana. 
Peteiro, L. M. (2001). Identidad corporativa: una perspectiva diferente para su estudio. Tesis de Licenciatura no publicada. Santa Clara, Universidad central "Marta Abreu" de las Villas.

Peteiro, L. M. (2008). Comunicación, Identidad e Imagen. Su importancia para el desarrollo estratégico de las organizaciones. Trabajo presentado en el evento "Casa de Cristal", Santa Clara.

Portal, R. y Amaya, H. (2005). Comunicación y Sociedad Cubana. Selección de lecturas. La Habana: Editorial Félix Varela.

Rey, L. (2002). La televisión: herramienta comunicativa para la comunidad", Tesis de maestría, Universidad de Camagüey.

Rey, L. (2009). La Televisión: Herramienta Comunicativa para la Comunidad. Aproximación a la actividad televisiva de Sagua Visión gestando la integración de lo local comunitario. Proyecto Doctoral. Centro de Desarrollo Comunitario Universidad Central "Marta Abreu" de las Villas. Santa Clara, Villa Clara.

Rodríguez, G. (1998). Investigación Cualitativa. Madrid: Editorial Paidós.

Saladrigas, H., Serrano, M. M. y Barbero, J. M. y otros. (2006). Comunicología. Temas actuales. La Habana: Editorial Félix Varela.

Saladrigas, H. (2007). Nuevas perspectivas y práctica en la investigación de la Comunicación Institucional, en Espacio: revista de la ACCS. (11).

Santana, J. (2002). ¿ldentidad visual versus identidad organizacional?, en Espacio: revista de la ACCS. (8).

Sanz, L. A. (1997). Integración de la identidad y la imagen de una empresa. La Habana: Editorial DEADE.

Sheinsohn, D. (1998). Dinámica de la comunicación e imagen corporativa. Argentina: Fundación OSDE.

Taylor, S. J. y R. Bodgan (1998). Introducción a los métodos cualitativos de investigación. Barcelona: Ediciones Paidós.

Timoteo, J. [s.f]. Historia y modelos de la comunicación en el siglo XX. La Habana: Editorial Pablo de la Torriente.

Trelles, I. (2001). Comunicación Organizacional. Selección de lecturas. La Habana: Editorial Félix Varela. 


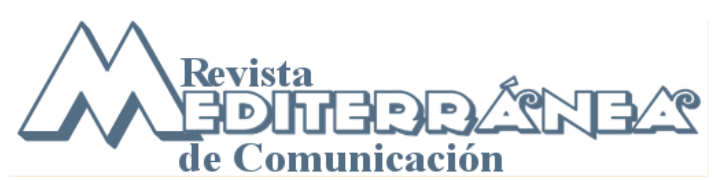

ISSN 1989-872X - Año2 (2011), pp. 140-170

Trelles, I. (2002). Bases teórico-metodológicas para una propuesta de modelos de gestión de comunicación en organizaciones. Tesis en opción del grado de Doctor en Ciencias de la Comunicación. Universidad de La Habana, Facultad de Comunicación.

Trelles, I., Meriño, J., Espinosa, A. (2005). Comunicación, imagen e identidad corporativas. Selección de lecturas. La Habana: Editorial Félix Varela.

Van Riel, C. (1997). Comunicación Corporativa. Madrid: Editorial Prentice Hall.

Villafañe, J. (1993). Imagen positiva. Gestión estratégica de la imagen de las instituciones. Madrid: Ediciones Pirámide.

Villafañe, J. (1999). La gestión profesional de la imagen. Madrid: Ediciones Pirámide S. A.

\section{Referencias en la red}

Cardoso, M. (2005). Importancia de la cultura y la comunicación institucional. Consultado el 20 de enero de 2009 en: www.losrecursoshumanos.com

Cardoso, H. (2002). Cultura y Comunicación Organizacional. El problema de la identidad corporativa en las auditorias de comunicación. Consultado el 24 de marzo de 2009 en: www.losrecursoshumanos.com

Cazau, P. (2006). Introducción a la investigación en Ciencias Sociales, (3.ed). Buenos Aires, consultado el 12 de marzo de 2006 en: WWW.GALEON.COM/PCAZAU

Cirigliano, C. (2007). Gestión de la comunicación interna en las organizaciones. Recuperado el 12 de enero de 2009 de http://www.rrppnet.com.ar/gestiondelacomunicacion.htm.

Fuenzalina, V. (1991). Televisión y Cultura Cotidiana, Santiago de Chile, CPU. Consultado el 20 de enero en www.rrppnet.com.ar/imageninstitucional.htm

García, H. (1997). Comunicación, vida cotidiana e identidades urbanas en S.L.P., en tiempos de globalización. Generación McLuhan. Consultado el 10 de febrero en www.imageninstitucional.com/

Mut, M. y Breva, E. [s.f]. De la identidad corporativa a la identidad visual corporativa, un camino necesario. Consultado el 20 de enero en www.rrppnet.com.ar/imageninstitucional.htm

Peteiro, L. M., Rodríguez, R. y Rodríguez, M. T. (2007). Reflexiones sobre cultura organizacional e instituciones en el mundo actual. Recuperado el 10 de febrero de 2009 de $\quad$ http://www.psicologiacientifica.com/bv/psicologia-271-1-reflexiones-sobre-culturaorganizacional-e--instituciones-en-el-mundo-actual.html\# 


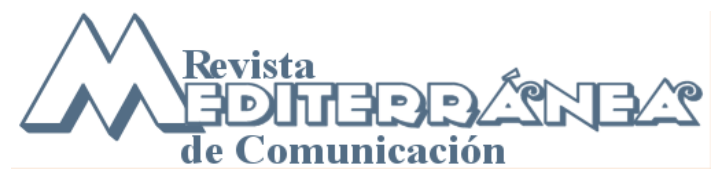

15. Sitios visitados

www.villafane.com

www.miespacio.org/cont/gi/imaper.htm

www.minas.upm.es/relext/proath.htm

www.losrecursoshumanos.com

www.rrppnet.com.ar/imageninstitucional.htm

$\underline{\text { www.imageninstitucional.com/ }}$ 